\title{
Trabalho de arte/Evento curatorial
}

Ricardo Basbaum*

\begin{abstract}
RESUMO: Neste texto são discutidas algumas questões relacionadas à prática curatorial, tendo como referência a relação entre o gesto de construção da exposição enquanto evento-obra e o contato com obra de arte como dispositivo singular: na medida em que as fronteiras entre exposição e obra se tornam cada vez menos nítidas, como organizar a ativação da exposição enquanto ativação da obra e vice-versa? Em que medida a construção da exposição, ao colocar em movimento interesses diversos, intensifica ou não o contato do visitante com a obra, quando este é cada vez mais capturado pela intensidade do evento-exposição? Do mesmo modo, serão discutidos os limites entre os papéis do curador e do artista, em proximidade também com o crítico, o historiador e outros agentes do circuito da arte contemporânea.
\end{abstract}

PALAVRAS-CHAVE: curadoria, construção da exposição, circuito de arte

ABSTRACT: In this text some issues related to the curatorial practice will be discussed, having as reference the relation between the gesture of building the exhibition as a work-event and the contact with the artwork as a singular device: considering that the borderlines between exhibition and artwork have become progressively blurred, how to organize the activation of the exhibition as the activation of the artwork and vice-versa? Considering that the making of the exhibition brings forward diverse interests, and that the exhibition visitor is more and more

\footnotetext{
* Ricardo Basbaum é artista, escritor, crítico e curador, doutor em Artes pela Universidade de São Paulo (2008) e professor do IACS/ UFF. Foi professor do Instituto de Artes da Uerj (1998-2016) e professor visitante da Universidade de Chicago (2013). Autor de Manual do artista-etc (Azougue, 2013), Ouvido de corpo, ouvido de grupo (Universidade Nacional de Córdoba, 2010). Participou da $20^{\mathrm{a}}$ e $25^{\mathrm{a}}$ Bienais de São Paulo (2002, 2012), Bienal de Kiev (2015) e da Documenta 12 (2007). Em 2014, realizou as exposições individuais nbp-etc: escolher linhas de repetição (Galeria Laura Alvim, Rio de Janeiro) e The Production of the Artist as a Collective Conversation (Audain Gallery, Vancouver).
} 
captured by the intensity of the event-exhibition, in which way does he or she have or not the contact with the artwork intesified as well? Also, the limits between the roles of the curator and the artist will be discussed, in close contact with the roles of the critic, the historian and the other agents belonging to the contemporary art system or circuit.

KEYWORDS: curatorship, exhibition making, art system

Percebo o curador como o principal agente a quem se atribui, hoje, a responsabilidade pela construção do evento: ou seja, aquele que toma para si - ou sua equipe - principalmente o trabalho de concepção e decisão relacionado à arquitetura e à engenharia dos meios e modos de construção do acesso e contato direto com as obras e demais situações autorais que irão ser colocadas e propostas. Neste sentido, mais do que ser o responsável pela "escolha" de artistas e trabalhos (principal função em geral identificada com a prática curatorial), o curador se singulariza como aquele que irá estabelecer caminhos de "confrontação", modular os modos de como se dará esse encontro, facilitar ou complicar a trama de deslocamento do visitante através do evento, organizar as partes interessadas diversas em sua complexidade própria. Tem-se assim o curador como peça-chave na mecânica de construção, regulação e administração da experiência com a obra de arte nas atuais condições de um circuito de arte hipertrofiado e hiperpresente, saturado em suas camadas de mediação e habitado por interesses múltiplos e conflitantes. Na medida em que esta condição da arte contemporânea (frente à qual não se deve recorrer a saudosismos) se naturaliza - isto é, ao se estabelecer e normatizar profissionalmente - acaba por se impor enquanto situação principal a ser desconstruída quando se quer, efetivamente, trabalhar na direção da singularidade de uma intervenção. Neste quadro, aqui rapidamente delineado, claramente estão em jogo diversas questões de importância decisiva para o que se quer fazer com a obra de arte e com sua vocação de objeto sensorial-conceitual produtor de diferença, ativador de regiões do comum e de compartilhamento na formação de coletivos sociais, articulador de memórias coletivas e portador de força instituinte.

Por um lado, é muito importante que a ação curatorial tenha a "forma exposição" como procedimento em aberto, sendo apenas uma de suas possibilidades: é preciso que esteja claro 
que o evento a ser construído poderá ter muitos formatos, a serem descobertos e inventados, de acordo com as relações que se quer estabelecer com os meios e linguagens utilizados, com a arquitetura do local e com os públicos que se deseja ativar. Tal caminho não deixa de "questiona[r] e investiga[r] o próprio conceito de curadoria e todo o sistema subjacente à produção de exposições" ${ }^{1}$, indicando o perfil do curador como o de um agente que idealmente se dedicaria ao livre enfrentamento dos modos de construção do evento-arte - isto é, o problema de como promover o contato entre sujeito fruidor e obra de arte, uma vez que este seria o limiar intensivo a ativar tal relação transformadora. É aqui que se deve reconhecer, frente ao evento curatorial em seus diversos formatos, a necessidade de se negociar continuamente os limites das diversas entidades que ali estão em encontro - principalmente, é claro, a territorialidade própria da obra de arte. Pois, por outro lado, ao mesmo tempo em que o evento ganha importância como elemento agregador construído pelo curador, a questão que se abre em toda sua força é aquela em torno dos contornos e limites da obra: onde esta se organiza, sem que se confunda com outras obras e com as linhas que definem o evento-obra? E mais, o que ali é de fato construção curatorial, expográfica, museográfica, influência do patrocinador corporativo ou estatal, em contraste (ou composição) com a ação contundente da proposição artística? Logo, por outro lado, é parte decisiva, hoje, do gesto curatorial o enfrentamento deste longo protocolo de negociações em que se regula um verdadeiro pacto de distribuição de territorialidades, frente ao qual devem sobreviver razoavelmente bem demarcados os contornos da obra de arte - ou o fetiche de sua presença - a promover as forças do encontro e do contato com o sujeito interessado. Não se trata de acordo simplório e é preciso que se reconheça o quão complexo se coloca este protocolo, no limiar do século XXI, quando se negocia com o campo da arte na plena potência esclarecida de suas relações com a macroeconomia e um amplo leque de interesses "participativos", todos concorrendo na formação do conflituoso conjunto de forças que articulam seus desejos no evento. O chamado mercado de arte movimenta cifras consideráveis, prestando-se sem qualquer pudor aos serviços do mercado financeiro e da especulação; ao mesmo tempo em que ali também combatem interesses histórico-críticos, deslocando a produção de valor para regiões de enfrentamento intelectual e político. E também, é claro, os interesses e responsabilidades próprios do artista frente aos rumos de sua produção contribuem para que se intensifiquem e fortaleçam as áreas de contato direto com a sociedade em seus processos de subjetivação, cujo engajamento é decisivo para que 
tenha na obra de arte um poderoso dispositivo de produção de problemas e de sensorialidade, articulando o pólo sensação-conceito em finas e precisas camadas desterritorializantes.

Quando se reconhece que na região de recepção da obra se trava uma forte batalha de interesses, percebe-se a mediação curatorial como papel que se foi construindo aos poucos², também na medida do desdobramento e da centralidade desta questão. É preciso lembrar como são decisivas as formulações do concretismo e neoconcretismo em relação à "abertura da obra" (questão em que ressoa também Umberto Eco) ${ }^{3}$ e as diversas modalidades participativas ali envolvidas, produzindo o reconhecimento do papel do espectador (e, um pouco mais tarde, do leitor) na ativação dos trabalhos. De certo modo, ainda resiste a noção de que o encontro efetivamente transformador é aquele entre sujeito fruidor e obra de arte - é ali, junto aos trabalhos, que são feitas as apostas significativas por parte daqueles agentes (artista, crítico, historiador, curador etc.) atentos ao risco e às mutações necessárias, apostando na obra como dispositivo principal. Entretanto, como vimos, cada vez mais ocorre que o público visitante se percebe em contato sobretudo com o evento expositivo, deixando de desenvolver atenção específica para com esta ou aquela obra. Nesse quadro, é o evento mesmo que é ativado - como um grande bloco - enquanto máquina que se quer "participativa", mobilizando diversas camadas próprias de sua constituição em dispositivos que, ao mesmo tempo em que vão se apresentando sempre como elementos receptores do visitante (este, sobretudo nas instituições de grande porte, deve ser "bem acolhido" pela museografia, expografia, setores educativos, discursos curatoriais etc.), são também pólos onde se projetam os diversos interesses em jogo em cada caso particular (trazidos por curadores, funcionários da instituição, patrocinadores, mercado, além dos artistas). Quando se tem a obra de arte tomada como agregado de interesses diversos - tal qual "conglomerado" de alteridades ${ }^{4}$ - e a exposição ou similar (onde a obra se lança em evento público) enquanto conjunto de camadas de mediação a constituir o evento em que também se aglutinam vontades individuais, institucionais e corporativas (não necessariamente coincidentes), percebe-se o quão "central" se qualifica hoje o processo (necessariamente em conjunto, eventualmente em coletivo) de construção/ produção do evento - típico hotspot do estado atual da economia da cultura. Principalmente aí concorre o "curador" - ou agente similar - ao desempenhar seu papel de organizador desta (nem sempre gigantesca, mas frequentemente no limite do espetáculo) ativa estrutura de contato, a receber o visitante e o público como organismo sensível a ser ativado, eventualmente posto em deriva. 
Como qualquer outra ação ligada à área artística, a curadoria funciona no limite entre o gesto de intervenção "sem recuperação possível pelo Espaço da Dominação onde se exerce", que "confere à arte um poder negativo específico", e a pragmática do circuito de arte (ou do mercado, em seu sentido amplo) que exige "compreensão da materialidade arte" para que "nela possa intervir com um cálculo de eficiência" ${ }^{5}$ - o estado da economia contemporânea da cultura parece impor a condição de uma ação necessariamente contraditória, oscilando - na medida de sua dificuldade e complexidade - entre "intervenção" e "cálculo". Se tal dinâmica não se esgota nos limites de um estrito "profissionalismo", a viger sob a normatividade da legislação jurídico-econômica, entretanto, é claro, a visibilidade crescente do personagem do curador é sintoma exatamente da progressiva profissionalização do circuito da arte contemporânea, em processo desde o final dos anos 1950 (condição visível na economia norte-americana a partir da arte Pop), em que as práticas da arte (mesmo em suas inflexões de vanguarda) se aproximam da indústria cultural; esse processo se consolida nos anos 1980, com o "capitalismo mundial integrado"6, que conduz à expansão do circuito de arte contemporânea através do planeta. Não é difícil perceber que tal processo de expansão não se completaria sem que se convocassem agentes organizadores e normatizadores, capazes de mediar a produção dos artistas junto à dinâmica voraz da ocupação de novos territórios pela nova dinâmica do capital - o curador está entre os personagens que são produzidos na velocidade destes desdobramentos: não simplesmente, é claro, enquanto funcionários da grande empresa transnacional da arte, mas sem dúvida se movimentando a partir do novo perfil profissional que vai se delineando e normatizando a partir de tais processos. É nesse sentido que se deve atentar sempre em relação à rigidez da divisão dos papéis para se perceber o que de fato está em jogo em cada ocasião em que são convocados os principais personagens que colocam em funcionamento o circuito de arte: afinal, se entre "obra" e "evento" as fronteiras são fluidas (onde a exposição é uma grande "obra" composta de trabalhos de arte), também as linhas que delimitam os perfis de curador, crítico, historiador e artista (entre outros papéis) entram em superposição, perdendo sua nitidez de fronteiras meramente segregadoras de práticas e territorialidades. Não é difícil reconhecer, nas tarefas de cada um destes "profissionais", áreas comuns em que se pratica o jogo da produção de sensações e invenção de conceitos, em que se constroem discursos e se praticam metodologias para ir ao encontro do outro. Ao propor que se repensasse a imagem do artista contemporâneo, em atuação a partir do final 
do século XX, enquanto "artista-etc"7, o que se quis foi indicar um movimento para além do "artista como funcionário do galerista" (ou seja, aquele artista que zela pelas fronteiras que dividem com clareza papéis e tarefas), de modo a enfatizar as zonas liminares de contato, onde personagens e papéis se hibridizam, mesclam e se superpõem uns aos outros.

Ao desempenhar suas tarefas junto ao evento de grande porte (bienais, trienais, documentas...), o curador pode estar a um passo de se perceber meramente como um grande gerente-geral, a organizar demandas tão distintas como comunicação e publicidade, patrocínio e financiamento, ao mesmo tempo em que as necessidades de cada obra presente são atendidas, em relação direta com a arquitetura da exposição e demandas museográficas e expográficas - sem esquecer da elaboração discursiva necessária, a mediar os tópicos acima em sua relação com narrativas históricas e críticas: percebe-se aí um conjunto de habilidades organizacionais e conceituais necessárias para o desempenho do papel. Entretanto, penso ser fundamental considerar as regiões em que as ações de curador e artista se misturam e se superpõem - no sentido de enfatizar a compreensão da construção do evento enquanto gesto de intensificação sensorial a privilegiar situações de contato com o visitante, em cada uma de suas camadas: é interessante que se considere o espectador como o agente que irá experimentar a exposição (por exemplo) camada por camada, atravessando membranas diversas até que se chegue de fato ao encontro da obra - sabendo-se que, frente à perda de nitidez das fronteiras entre obra e evento, não se pode afirmar a rigor onde aquela de fato se inicia e começa a funcionar. Nesse sentido, uma exposição se configuraria como imenso agregado vibratório em que suas diversas partes e camadas - seja obra de arte, seja elemento de mediação, desenho ou construção da exposição - tornam-se lugares de experiência sensível, regiões de encontro e deriva a serem ativadas. Deve-se conceber um funcionamento descentrado, é claro, em que a hierarquia da obra como dispositivo especial e mais importante é horizontalizada, de modo provocador, acreditando que a condição imersiva do visitante seria potencializada a todo instante no enfrentamento de cada camada ali desdobrada e construída - se os limites estão em permanente negociação, as obras e demais membranas se distribuem ao largo do espacialidade do evento, no percurso da visitação, remetendo sempre umas às outras, potencializando-se ou produzindo desvios e curto-circuitos. Percebe-se aí o quão importante seria a mobilização de linguagens envolvidas na crítica institucional, conceitualismo, experimentalismo sensorial, performance e corpo, especificidade do lugar etc. - no 


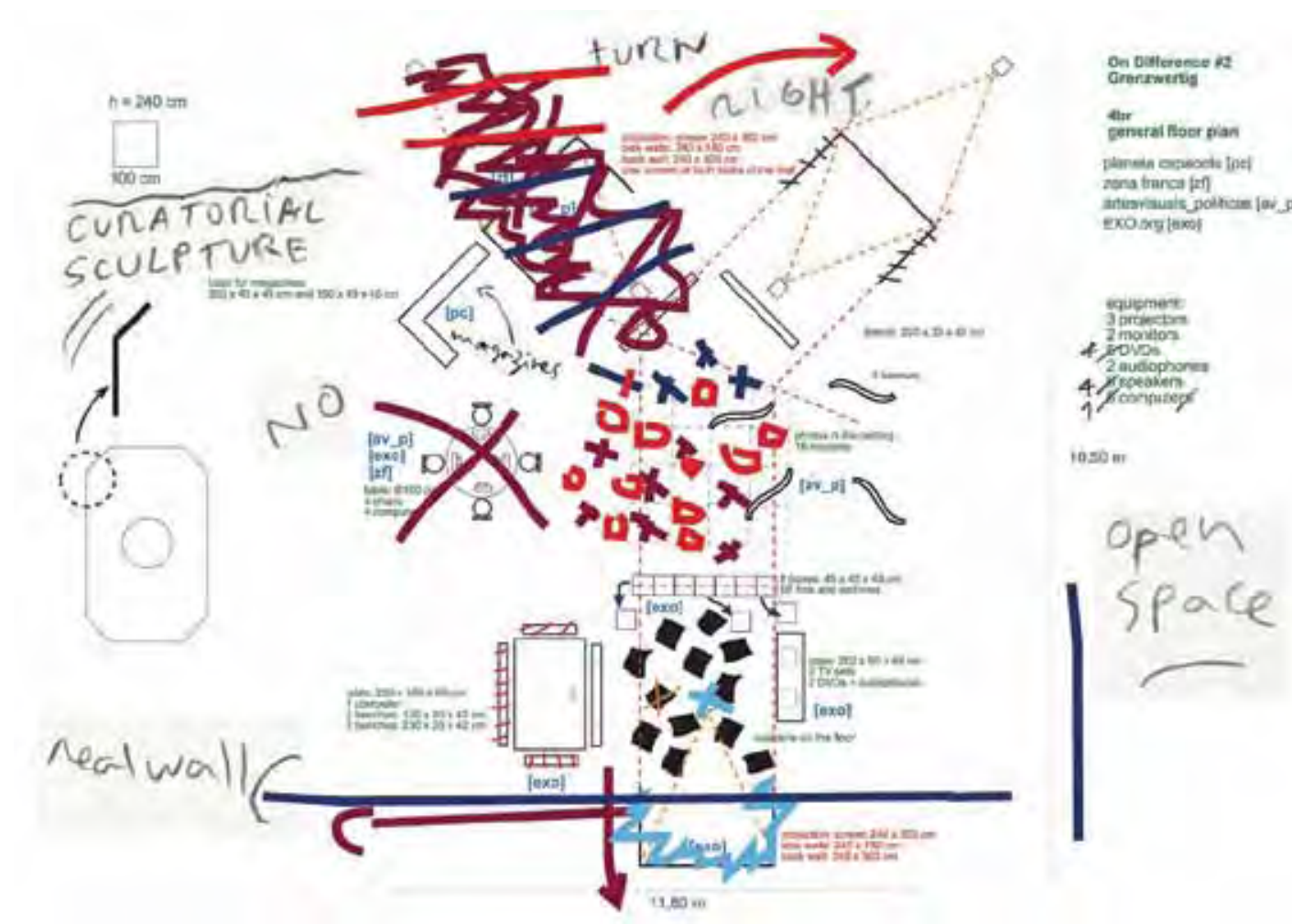

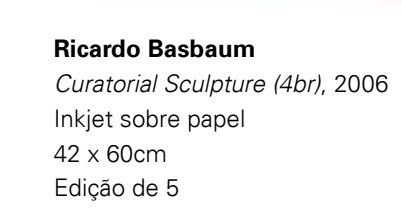


sentido de compreender a exposição como um lugar de envolvimento, conduzindo o visitante em um labirinto produtivo em que estaria em jogo a economia da experiência, em sentido amplo, enquanto produção de valor, e a compreensão dos mecanismos de construção do evento em sua materialidade, em contato com o "mundo lá fora". Tudo isso, enfim (camadas e camadas em seu reviramento dentro-fora), para que se possa ativar as obras como parte do mesmo movimento de ativar a exposição: mobilizar efeitos indiretos, distribuídos entre as diversas áreas e tarefas do evento, ambicionando algum modo de funcionamento conjunto das diversas instâncias. Sem dúvida que tal personagem, no desenvolvimento de sua atuação, requereria competências múltiplas -principalmente habilidade no manejo da experiência sensorial, compreensão dos gestos de confronto da obra de arte e noção de articulação diagramática do funcionamento do sistema de arte - um cuidadoso manejo da difícil equação que combina "cálculo eficiente" e negatividade da "intervenção". Este personagem híbrido curador-artista funcionaria como "agente regulador" principal frente aos fluxos colocados em movimento pelo evento-exposição.

Assim, quando se discute a questão da formação dos atores e agentes do campo da arte, considero cada vez mais importante que se tenham efetivamente espaços comuns de aprendizado e trocas para artistas, críticos, historiadores e curadores - e demais personagens. Mais do que explorar as especificidades de cada prática - as quais emergem a todo momento no calor da atividade concreta de trabalho - vejo como extremamente produtivo, nas condições atuais, uma ampla prática laboratorial formativa em que se poderia experimentar, de modo direto, o deslocamento entre os diversos papéis e o desenvolvimento de ações híbridas de problematização e investigação. Certamente que cada área se diferencia por metodologias e referências próprias, que devem ser potencializadas e inevitavelmente aprofundadas com o desenvolvimento do trabalho; entretanto, a condição experimental de deslocamento entre os papéis indica não apenas o quanto estes diferentes campos, hoje, se constituem a partir dos problemas comuns de um pensamento contemporâneo avançado - que produz ferramentas de intervenção e mobiliza a fabricação do sujeito enquanto construção de si - como também têm sua diferenciação banalizada por questões meramente normativas e convencionais da divisão do campo profissional de trabalho a partir de atribuições específicas de cada prática. Ocorre aí um interessante desafio de reinvenção de fazeres - já em curso - que tem colocado em deriva a mera divisão territorial de competências, apontando para formações onde os 
campos se reorganizam uns em relação aos outros, a partir do mútuo contato, hibridizações e misturas. Esta é uma perspectiva que parece instigante, não apenas pela reinvenção de campos, metodologias e competências, mas principalmente por indicar outras configurações de circuito e perfis institucionais novos, possíveis. Acredito que tais processos já se encontrem em andamento.

\section{Notas}

1 HOFFMANN, Jens. A exposição como trabalho de arte. Concinnitas, Rio de Janeiro, Instituto de Artes/Uerj, n. 6, jul. 2004.

2 Embora em geral se considere a ocorrência de um acirramento dos debates em torno da ação curatorial a partir dos anos 1970 - em aceleração crescente até o final do século XX -, parece ser muito interessante considerar esta forma de ação (ou seja, a construção do evento em suas camadas de mediação) como estando em elaboração contínua desde o momento em que se tem em conta as necessidades de negociar a aparição pública da obra de arte, em seu processo de constituição de autonomia junto à modernização das sociedades. O livro The Avant-Garde in Exhibition - New Art in the 20th Century, de Bruce Altshuler (University of California Press, 1998), é apenas uma das cada vez mais frequentes publicações que procuram investigar a construção de exposições - com destaque para a série Exhibition Histories, da editora Afterall (Cf. http://www.afterall.org/books/exhibition.histories/exhibition-histories acesso em 05/01/2016).

3 ECO, Umberto. Obra aberta. São Paulo: Perspectiva, 1976 [1962].

4 Cf.: BASBAUM, Ricardo. Quem é que vê nossos trabalhos. In: FERREIRA, Glória; PESSOA, Fernando (orgs.). Criação e crítica. Vila Velha: Museu Vale; Rio de Janeiro: Suzy Muniz Produções, 2009. (Seminários Internacionais Museu Vale; 4)

5 Passagens extraídas de BRITO, Ronaldo. O moderno e o contemporâneo (o novo e o outro novo). In: Arte Brasileira Contemporânea - Caderno de Textos 1. Rio de Janeiro: Funarte, 1980.

6 Cf.: GUATTARI, Félix. O capitalismo mundial integrado e a revolução molecular. In: ROLNIK, Suely (org.). Revolução molecular. pulsações políticas do desejo. São Paulo: Brasiliense, 1985. Trata-se do impulso da economia neoliberal, também percebido como "capitalismo cognitivo," "informacional" ou "afetivo".

7 Cf.: BASBAUM, Ricardo. Amo os artistas-etc. In: Manual do artista-etc. Rio de Janeiro: Azougue, 2013.

\section{Referências}

BASBAUM, Ricardo. Quem é que vê nossos trabalhos. In: FERREIRA, Glória; PESSOA, Fernando (orgs.). Criação e crítica. Vila Velha: Museu Vale; Rio de Janeiro: Suzy Muniz Produções, 2009. (Seminários Internacionais Museu Vale; 4)

BASBAUM, Ricardo. Amo os artistas-etc. In: Manual do artista-etc. Rio de Janeiro: Azougue, 2013. 
BRITO, Ronaldo. O moderno e o contemporâneo (o novo e o outro novo). In: Arte Brasileira Contemporânea - Caderno de Textos 1. Rio de Janeiro: Funarte, 1980

ECO, Umberto. Obra aberta. São Paulo: Perspectiva, 1976.

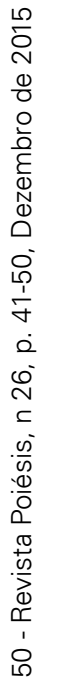

GUATTARI, Félix. O capitalismo mundial integrado e a revolução molecular. In: ROLNIK, Suely (org.). Revolução molecular: pulsações políticas do desejo. São Paulo: Brasiliense, 1985.

HOFFMANN, Jens. A exposição como trabalho de arte. Concinnitas, Rio de Janeiro, Instituto de Artes/Uerj, n. 6, jul. 2004. 